\title{
LA INDEMNIZACIÓN EN LAS SERVIDUMBRES PREDIALES ELÉCTRICAS
}

\begin{abstract}
Alejandro Vergara Blanco ${ }^{1}$
Refiérese este trabajo a las limitaciones, perjuicios y gravámenes que sufre un predio a raiz de la constitución de servidumbres eléctricas de postes y líneas aéreas, y a las subsecuentes indemnizaciones que, según la ley, tendrá derecho el dueño de tal predio sirviente (I). Además, se precisará el correcto sentido y alcance de la expresión «terrenos ocupados» que utiliza el art. 69 del DFL1/1982, Ley General de Servicios Eléctricos (en adelante: LGSE), cuya relevancia surge por el mandato sustantivo que contiene en orden a un aumento del monto de la indemnización que debe pagársele al dueño del predio sirviente en las servidumbres eléctricas (II). En fin, se hará referencia a la posibilidad jurídica de considerar como perjuicio indemnizable a lo que se denomina «influencia indirecta» y a los impactos ambientales (III).
\end{abstract}

\section{FIJACIÓN DE INDEMNIZACIÓN POR PERJUICIOS OCASIONADOS POR POSTES Y LÍNEAS ELÉCTRICAS}

Trata este apartado del sistema indemnizatorio de las servidumbres forzosas para la instalación de "postaciones y líneas eléctricas» (según la terminología de la ley: art. $2 \mathrm{n}^{\circ} 4$ b) LGSE); las que favorecen a un concesionario de transporte de energía eléctrica, y que gravan a los predios superficiales (1), los dueños de los cuales podrán recibir una indemnización por los perjuicios que se les cause (2).

1. Servidumbres que crea la concesión eléctrica para instalaciones eléctricas.

Las concesiones eléctricas, según la ley «otorgan el derecho a imponer (...) servidumbres» (art. 14 inc. $1^{\circ}$ LGSE), a las que quedan sujetas (en lo que interesa en este caso), «las heredades, para la construcción, establecimiento y explotación de las instalaciones y obras anexas que posean concesión [eléctrica]) (art. 4 a) LGSE). Estas servidumbres, tanto en su constitución como en su ejercicio (art. 14 inc. $2^{\circ}$ LGSE), se rigen por normas especiales (que contiene la LGSE, en sus arts. 47 a $71)^{2}$.

Los tipos concesionales que regula la LGSE, están dirigidos a crear derechos de utilización del suelo ajeno. Así, en el caso de concesiones para establecer líneas de transporte de energía eléctrica (en que es necesario instalar postes y torres, hacer

\footnotetext{
${ }^{1}$ Abogado, Doctor en Derecho, Profesor de la Pontificia Universidad Católica de Chile.

${ }^{2}$ Véase $\$ \sigma$ (creación administrativa) y $\$ 12$ (caracterización general),
} 
caminos de servidumbres, y otras obras anexas), cuando existe una concesión otorgada, nacen, al mismo tiempo, a favor del concesionario unos derechos de utilización del suelo; tratándose de suelo privado, lo que nace es un derecho real de servidumbre que grava a predios ajenos.

Entonces, si el título concesional eléctrico, crea y constituye, por el sólo ministerio de la ley, un gravamen específico que pesa sobre los terrenos privados que la ley denomina servidumbres; este gravamen a su vez constituye un derecho del concesionario que lo habilita para la utilización de tales terrenos.

Si bien las servidumbres eléctricas se constituyen usualmente por la vía administrativa (esto es, en el acto concesional), también puede realizarse por la vía convencional ${ }^{3}$. En el caso que la servidumbre esté constituida en el acto concesional, por razones de interés público, es posible su ejercicio inmediato, «sin perjuicio de las acciones judiciales que bubiere pendientes» (art. 59 LGSE); pudiendo el concesionario eléctrico tomar posesión del terreno en definitiva una vez cancelado el valor que fije una comisión de Hombres Buenos (art. 66 LGSE), aún antes de haber acuerdo sobre el monto de las indemnizaciones a pagar.

Así, no obstante estar constituida la servidumbre por la vía concesional, o incluso existir posesión del terreno respectivo, puede persistir entre el concesionario eléctrico y el dueño del predio sirviente un desacuerdo sobre el valor de los terrenos afectados, $y$, subsecuentemente, sobre el monto de la indemnización que por los perjuicios deba pagar el concesionario. En tal caso, como se adelantó, se debe proceder a la designación de una comisión de Hombres Buenos, para que «practique el avaluo de las indemnizaciones que deben pagarse al propietario del predio sirvientes (art. 62 LGSE). Esta comisión de Hombres Buenos debe fijar el avalúo de las indemnizaciones según el tipo de servidumbres (limitaciones) que se hayan constituido.

2. Marco legal indemnizatorio del que fluyen atribuciones de Comisión de Hombres Buenos (y del juez).

El procedimiento de constitución y atribuciones de la comisión de Hombres Buenos se encuentran reguladas especialmente en los arts. 62 a 69 LGSE. De partida, el art. 62 LGSE establece que: "Si no se produjere acuerdo entre el interesado y el dueño de los terrenos sobre el valor de éstos, el Ministro del Interior designará una comisión compuesta de tres Hombres Buenos para que, oyendo a las partes, practique el avalúo de las indemnizaciones que deben pagarse al propietario del predio sirviente. En este avalúo no se tomará en consideración el mayor valor que puedan adquirir los terrenos por las obras proyectadas».

En esta norma quedan fijadas las atribuciones de esta comisión, que se dirigen fundamentalmente a un objetivo: efectuar la determinación del valor de lo

\footnotetext{
${ }^{3}$ Vid. antecedentes generales sobre la constitución administrativa y convencional de servidumbres eléctricas, respectivamente, en $\$ 6$ y $\$ 13$.
} 
debido al dueño del predio sirviente; en palabras de la ley: las indemnizaciones que «deben» pagarse a tal propietario.

Y lo que «debe» pagarse es evidentemente lo que señala la ley; y la determinación de lo que es lo debido, a raiz de las limitaciones, perjuicios o gravámenes que sufre el dueño del suelo, está establecido en los arts. 68 y 69 LGSE. La Comisión de Hombres Buenos debe simplemente determinar el valor de tales perjuicios en cada caso concreto; determinación en la que deben seguir las hipótesis de limitaciones indemnizables que de manera taxativa y restrictiva señala la ley.

De este modo, respecto de la procedencia legal de toda indemnización a raíz de una servidumbre eléctrica, la Comisión de Hombres Buenos sólo puede tasar terrenos y fijar un monto determinado de indemnización por cada concepto, siempre y cuando la limitación respectiva se encuadre en alguna de las que señala la ley en el art. 68 LGSE, que se analiza en seguida.

\section{Objetos y finalidades de limitaciones de predios ajenos.}

Ahora, ¿con qué objetos o finalidades es posible limitar los predios ajenos en materia eléctrica? Al respecto, el art. 50 LGSE establece que:

«Las concesiones de líneas de transporte, subestaciones y de servicio público de distribución crean en favor del concesionario las servidumbres:

1. Para tender líneas áreas o subterráneas a través de propiedades ajenas;

2. Para ocupar los terrenos necesarios para el transporte de la energía eléctrica, desde la central generadora o subestación, hasta los puntos de consumo o de aplicación;

3. Para ocupar y cerrar los terrenos necesarios para las subestaciones eléctricas, incluyendo las habitaciones para el personal de vigilancia».

Es el caso de una concesión para establecer lineas de transporte de energía eléctrica, es que son necesarios, esencialmente, "postes», "torres», "lineas aéreas» eléctricas (vid. arts. $2 \mathrm{n}^{\circ}$ s. 1 letra c), y 4 letra a), 50 y $68 \mathrm{n}^{\circ} 1$ LGSE), los que deben instalarse en el suelo, ocupando terreno ${ }^{4}$. En suma, el concesionario de transporte de energía eléctrica, puede:

a) instalar postes y torres (ocupando el terreno necesario para ello); $y$,

b) «tender» líneas aéreas (lo que se hará «a través» de propiedades ajenas).

Ahora, si se trata de un concesionario que, según los planos de servidumbres aprobados por el decreto concesional, puede instalar postes y torres en propiedad ajena, la que también será r ruzada por las líneas aéreas que se sustenten en tales postes y torres, surge el problema de la fijación de las indemnizaciones.

\footnotetext{
${ }_{4}^{4}$ Si bien este análisis se realiza respecto de alíneas» y demás instalaciones de transporte de energía eléctrica, es aplicable a toda instalación eléctrica (vid. art. 68 LGSE); ya sea relativa a generación o transporte de energía eléctrica, a partir de los términos de los arts. $2 n^{\circ} 4,14,47$ y 48 I.GSE.
} 
4. Reglas para determinación de indemnizaciones respecto de predio sirviente que debe soportar instalaciones eléctricas.

Luego de fijar los gravámenes a que están sujetas las heredades a favor de las instalaciones eléctricas, según hemos visto (art. 50 LGSE), regula la ley de manera especifica las limitaciones que dan lugar a indemnizaciones. Estas indemnizaciones a que tiene derecho el dueño del predio sirviente con motivo de las servidumbres constituidas a favor del concesionario eléctrico, serán el resultado económico de la determinación de su avalúo (arts. 68 y 69 LGSE), el que debe ser realizado por la comisión de Hombres Buenos (o por el juez en caso de reclamo: arts. 62 y 71 LGSE).

Los criterios legales consisten en una enumeración taxativa de los tres tipos de perjuicios, limitaciones o gravámenes que sufre el predio sirviente, de los que se derivan los únicos valores a indemnizar (a); surge además de la ley un criterio adicional: su relación a terrenos determinados (b).

a) Limitaciones, perjuicios o gravámenes por los que tiene derecho a indemnización el dueño del predio sirviente están expresa y taxativamente señalados por la ley.

Los perjuicios indemnizables en el caso de servidumbres eléctricas se encuentran enumerados taxativamente en el art. 68 LGSE, que establece:

«El dueño del predio sirviente tendrá derecho a que se le pague:

1. El valor de todo terreno ocupado por las obras hidroeléctricas, incluidas las de embalse y estanques, por los postes y las torres de las líneas, por las zanjas de las líneas subterráneas, por los edificios, y por los caminos de acceso, según los planos de servidumbre;

2. El valor de los perjuicios ocasionados durante la construcción de las obras o como consecuencia de ellas o del ejercicio de las servidumbres. Igualmente el valor de los perjuicios que causan las líneas aéreas;

3. Una indemnización por el tránsito que el concesionario tiene derecho a hacer para los efectos de la custodia, conservación y reparación de las líneas. Esta indemnización no podrá ser superior al valor de una faja de terreno de dos metros de ancho, en la parte del predio ocupado por las líneas.

$\mathrm{Si}$ al constituirse una servidumbre quedaren terrenos inutilizados para su natural aprovechamiento, el concesionario estará obligado a extender la servidumbre a todos estos terrenos».

Se deriva el carácter taxativo de esta norma de los propios términos en que se encuentra redactada: «[e]l dueño del predio sirviente tendrá derecho a que se le pague (...)», y por el hecho de contener una enumeración. Estas reglas legales tienen distinta naturaleza, y tienden a delimitar o excluir criterios económicos de avaluación; así:

$1^{\circ}$ es una regla de exclusión la que establece que en el avalúo practicado por la comisión de Hombres Buenos ino se tomarả en consideración el mayor valor que puedan adquirir los terrenos por las obras proyectadas》) (art. 62 inc. $1^{\circ}$ in fine LGSE); y, 
$2^{\circ}$ es una regla de limitación la contenida en el art. $68 \mathrm{n}^{\circ} 3$ LGSE, en que se establece que la indemnización por el tránsito que el concesionario tiene derecho a hacer para los efectos de la custodia, conservación y reparación de las líneas «no podrá ser superior al valor de una faja de terreno de dos metros de ancho, en la parte del predio ocupado por las lineass.

En suma, la ley delimita o excluye los criterios que deben considerarse para fijar indemnizaciones por servidumbres eléctricas, criterios éstos que son imperativos para la comisión de Hombres Buenos y para el juez.

b) Criterio legal adicional en cuanto al contenido de las servidumbres: su relación a terrenos determinados. El contenido de las servidumbres eléctricas dice relación con los derechos que otorga, y éstos, para que sea posible su ejercicio, dicen relación con un terreno determinado; terreno éste que en cada caso debe quedar precisado en los planos especiales de servidumbres que el peticionario debe adjuntar a la solicitud de concesión, si desea que se constituyan en su favor las servidumbres que establece la ley. Por tal razón el art. 47 LGSE establece que «[t]odas las servidumbres que señalen los decretos de concesiones eléctricas definitivas se establecerán en conformidad a los planos especiales de servidumbres que se hayan aprobado en el decreto de concesión.

En general, como lo señala en tal carácter el art. $2^{\circ} n^{\circ} 4$ a) LGSE, el contenido de las servidumbres está dirigido sustantivamente a sujetar a «las heredades, para la construcción, establecimiento y explotación de las instalaciones y obras anexas que posean concesión).

Entonces, este criterio de vinculación a un terreno "determinado», se transforma en un presupuesto básico: antes que nada se debe avaluar y tasar el terreno respectivo, pues en relación a tal tasación y a la superficie comprometida, se fijarán los valores de los terrenos que sufren gravamen o limitación.

En fin, cabe precisar que, en el caso de postes y líneas aéreas, además de la obligación central de tener que soportar la servidumbre de que su terreno sea "ocupado" por la instalación de postes y de que sean tendidas "a través» de tal terreno líneas aéreas (limitaciones que autorizan los arts. $19 \mathrm{n}^{\circ} 24$ Constitución Política (en adelante: CP) y arts. 50, 53, 55, 57 y 58 LGSE), el dueño del suelo tiene una obligación de no hacer establecida en el art. 56 LGSE, que consiste en no hacer «plantaciones, construcciones ni obras de otra naturaleza que perturben el libre ejercicio de las servidumbres\%. En caso de incumplimiento de esta obligación, el concesionario eléctrico podrá subsanar este hecho «a costa del dueño del suelos.

\section{Indemnizaciones a las que tiene derecho el dueño del predio sirviente.}

Como se ha dicho, el art. 68 LGSE, establece las indemnizaciones a las que tiene derecho el dueño del predio. Dado que es la única norma que se refiere a este tema (junto al art. 69 LGSE, que se refiere a un «aumento» de tales valores en un

\footnotetext{
${ }^{5}$ Art. 56 LGSE.
} 
caso específico), y por los términos en que está redactado, se puede concluir que el dueño del predio sólo tiene derecho a que se le pague lo que ella establece. O dicho de otro modo: las limitaciones contempladas en esta norma son las únicas hipótesis que dan lugar a indemnizaciones; $y$, subsiguientemente de las únicas que se derivan obligación de pago por el titular de las servidumbres eléctricas.

En suma, de acuerdo a la ley, la sítuación de los distintos terrenos de un predio gravado con servidumbres eléctricas, en cuanto a las limitaciones que sufre, es la siguiente:

$1^{\circ}$ Terrenos «ocupados». Son los terrenos que están ocupados por instalaciones y obras eléctricas, como postes, torres y edificios; incluyéndose los caminos de acceso. Se debe pagar el «valor total del terreno ocupado» (art. $68 \mathrm{n}^{\circ} 1$ LGSE).

El fundamento de la indemnización es la «totals ocupación física de tales porciones del terreno, el que queda entonces impedido de todo otro uso, por lo cual se debe indemnizar el valor (totab) de la parte del predio ocupado; esto es, el cien por ciento de la tasación de esa parte (con un aumento del veinte por ciento), según fluye de los arts. $68 \mathrm{n}^{\circ} 1$ y 69 LGSE.

Es necesario extender la servidumbre e indemnizar al propietario del terreno que «se constituye servidumbre», a aquellos otros terrenos que queden rinutilizados para su natural aprovechamienton (art. 68 inc. final LGSE).

En fin, contempla la ley una regla de excepción: el criterio legal de establecer un aumento del valor de la indemnización fijada por la comisión de Hombres Buenos respecto de los terrenos ocupados (arts. 65 ab initio y 69 LGSE), que se analiza infra.

$2^{\circ}$ Perjuicios durante la construcción. Son esencialmente transitorios, y se tasarán de acuerdo a su naturaleza y duración, pues se trata del valor de los perjuicios que se originen "durante la construcción de las obras».

$3^{\circ}$ Faja de proteción o de servidumbre. Se trata del efecto «del ejercicio de las servidumbres», incluyendo especialmente «el valor de los perjuicios que causan las líneas aéreas»).

En este caso, es evidente que el terreno no es físicamente "ocupado», sino «cruzado» por las lineas aéreas, y en eso consiste el gravamen; $y$, dado que el terreno no es «ocupado» físicamente por obras o instalaciones, la ley no fija como indemnización el valor de stodon el terreno (como en el caso anterior) sino el valor de los perjuicios por las limitaciones que sufre el terreno, lo que debe ser tasado por los peritos. En estos casos, usualmente se establece un valor por la limitación consistente en no poder hacer «plantaciones, construcciones ni obras de otra naturaleza que perturben el libre ejercicio de las servidumbres» (art. 56 LGSE), teniendo en consideración que ello no implica que estos terrenos queden inutilizados.

Es la llamada (faja de protección» o «faja de servidumbre» de las líneas aéreas, y el terreno que está al rededor de ellas, como ha dicho la jurisprudencia, «no queda 
totalmente inutilizado», por lo que «estas limitaciones legales no permiten una indemnización del cien por ciento del valor del terrenos."

En estos terrenos que están directamente bajo el tendido eléctrico, se debe pagar «el valor de los perjuicios que causan las líneas aéreas» (art. $68 \mathrm{n}^{\circ} 2$ inc. $2^{\circ}$ LGSE).

$\mathrm{La}$ indemnización que procede es aquella que corresponde a los perjuicios ocasionados por la limitación establecida en el art. 56 LGSE, indemnización cuyo fundamento es la parte final del $\mathrm{n}^{\circ} 2$ del art. 68 LGSE, que contempla como hipótesis de limitación o gravamen a «los perjuicios que causan las líneas aéreas».

Respecto de estos terrenos existe una limitación consistente en una obligación de no hacer para el dueño del predio sirviente, a pesar de que no hay una ocupación física por obras o instalaciones eléctricas. Esta limitación sólo afecta los terrenos que están directamente bajo las líneas, y a los edificios y construcciones situadas a 2,50 metros a cada uno de sus lados.

Lo que se incrementa en un centímetro por cada kilovatio de tensión en exceso sobre 26 kilovatios; así, para una línea de 220 kilovatios las limitaciones antes señaladas para el dueño del predio sirviente se extienden a una faja de terreno de 4,44 metros a cada lado de la línea aérea (conductor), como lo señala el artículo 109.2 de la Norma Técnica de Instalación de Corrientes Fuertes [en adelante: NSEG S, E.n. 71]. Esta limitación, que debe ser contemplada en toda indemnización, comprende no sólo los edificios y construcciones sino que, además a los arbolados cuya altura no debe ser superior a cuatro metros (artículo 111 de la Norma Técnica de Instalación de Corrientes Fuertes [NSEG S. E.n. 71]).

Así, la limitación establecida en el art. 56 LGSE, que debe ser indemnizada según el art. $68 \mathrm{n}^{\circ} 2$ LGSE, está determinada en una superficie aproximada de 5 metros a cada lado de las líneas aéreas (conductores). Es la denominada «franja de servidumbres en la práctica, la que suele determinarse en los planos de servidumbre con un ancho de 40 metros; esto es, cubriendo más superficie que la exigida por los arts. 109 y 111 de la NSEG S. E.n. 71.

Asi, las hipótesis que quedan comprendidas en la ley como limitaciones que provocan perjuicios son sólo dos: por una parte, los derivados de la prohibición de hacer plantaciones, construcciones u obras de cualquier naturaleza que perturben el libre ejercicio de las servidumbres (art. 56 LGSE) y que se contempla entre los criterios de tasación y valoración, como sfranja de servidumbres (a); y, por otra parte, la inutilidad de los terrenos que pudiera derivarse (b).

a) Limitaciones y perjuicios de la sfranja de servidumbres. La denominada en la práctica «franja» o «faja de servidumbre» o «faja de protección» (art. 56 LGSE), es una porción de terreno en la que no se podrán hacer plantaciones. Pero esta faja de

\footnotetext{
${ }^{6}$ Caso RZeman an Chilectrou, Corte de Apelaciones de San Miguel, 26 de septiembre de 1996, reproducida en esa parte por la sentencia de reemplazo de la Corte Suprema, 22 de septiembre de 1997, considerando $14^{\circ}$ (inédita).
} 
terreno no puede ser indemnizada como suelo inutilizado. La jurisprudencia (caso "Zeman con Chilectra", de 1997), ha señalado al respecto lo siguiente:

"Que estos sentenciadores discrepan de la opinión del perito respecto de la faja de protección, que es aquella dentro de la cual el afectado «no podrá hacer plantaciones, construcciones ni obras de otra naturaleza que perturben el libre ejercicio de las servidumbres establecidas por esta ley", como lo señala el artículo 56 del DFL $n^{\circ} 1$, pues dicha faja, que en este caso es de 40 metros de ancho por la longitud total de la línea (1.110 metros lineales), o sea, 44.400 metros cuadrados, no queda totalmente inutilizada para la explotación agrícola del predio, pues en ella pueden subsistir árboles frutales de una altura no superior a 4 metros o podrían efectuarse otras explotaciones agrícolas o pecuarias, aunque ella queda bastante limitada, por cuanto en lo sucesivo y mientras existan plantaciones o siembras no se podrán realizar fumigaciones aéreas por la seguridad de las instalaciones eléctricas, por lo que esta Corte considerará que si bien estas limitaciones legales no permiten el pago de una indemnización del $100 \%$ del valor del terreno, para los efectos de la indemnización que debe fijarse en conformidad a la normativa del artículo 68 de la ley eléctrica considerará que ella debe corresponder al $60 \%$ del valor del terreno involucradom.

Entonces, la limitación que produce en este sentido la línea es la señalada en el art. 56 LGSE, y ese es el perjuicio que debe ser indemnizado.

b) Sólo son indemnizables los terrenos que queden inutilizados para su natural aprovechamiento. Finalmente, no debe perderse de vista al interpretar todas las normas relativas a las indemnizaciones que deben pagarse al dueño del predio sirviente que, por una parte, el concesionario eléctrico es titular de servidumbres y por lo tanto, podría decirse que si bien el establecimiento y ejercicio de las servidumbres pueden ocasionar efectos o impactos, se trata de efectos «autorizados por la ley», que deben considerarse «lícitos»; por otra parte, el dueño del predio sirviente está obligado a soportar estos efectos en función de la utilidad pública involucrada en la generación, transporte y distribución en su caso, de energía eléctrica (art. $19 \mathrm{n}^{\circ} 24$ CP: función social de la propiedad).

En suma, el valor de los perjuicios ocasionados por las líneas eléctricas que se tienden en una propiedad dice estricta relación con las limitaciones que sufre la propiedad y con los derechos que se crean a favor del concesionario eléctrico a raiz de tales líneas; y dado que la ley especifica que tales limitaciones sólo consisten en la imposibilidad de hacer plantaciones que perturben el ejercicio de las servidumbres, en el menor valor global del terreno o en su inutilización, sólo puede fijarse un valor de indemnización en caso que efectivamente se ocasionen tales limitaciones.

$4^{\circ}$ Franja de tránsito. La indemnización por este concepto se refiere al tránsito que tiene derecho a hacer el concesionario eléctrico para la conservación, custodia y reparación de las líneas. Como tal, la limitación que sufre el predio por el derecho al tránsito del concesionario no se refiere sino indirectamente a una franja de terreno 
determinado: la limitación y gravamen consiste en soportar este tránsito para los fines que establece la ley (arts. 55 inc. $1^{\circ}$ y 57 LGSE); y si se habla de (franjas de tránsito es porque la ley ha establecido como criterio, de un modo ficto, para la determinación del monto máximo de esta indemnización, la siguiente regla: «esta indemnización no podrá ser superior al valor de una faja de terreno de dos metros de ancho, en la parte del predio ocupado [ucruqado», mas bien] por las lineas» (art. $68 \mathrm{n}^{\circ} 2$ in fine LGSE). Regla ficta que no cambia la naturaleza de esta limitación: soportar el derecho a tránsito, el que se efectúa por un camino de acceso.

En suma, estos son los tres tipos de limitaciones que la ley contempla como legítimamente indemnizables; enumeración legal ésta que es taxativa.

En efecto, como ya se señaló, el encabezamiento del art. 68 LGSE deja claramente establecido que aquellas limitaciones son las únicas a que tiene derecho de pago el dueño del predio sirviente. En otras palabras, no hay otras limitaciones por las que el dueño del predio tenga derecho a que se le pague. Y si llegara a considerarse que son limitaciones no indemnizadas, ellas quedarán comprendidas, entonces, en la función social de la propiedad (art. $19 \mathrm{n}^{\circ} 24$ inc. $2^{\circ} \mathrm{CP}$ ), dado que en ningún caso la afectan en su esencia (art. $19 \mathrm{n}^{\circ} 26 \mathrm{CP}$ ). Esta norma contempla las únicas hipótesis de limitaciones, gravámenes o perjuicios que pueden indemnizarse, y para determinar su alcance debe analizarse cada uno de los supuestos que contempla.

\section{Sólo es posible indemnizar respecto de terrenos afectos a servidumbre.}

Resulta claro que las servidumbres eléctricas dicen relación con terrenos determinados, los cuales quedan afectos a una limitación: de ahí el carácter taxativo del art. 68 LGSE.

Además, no debe olvidarse que los casos contenidos en el art. 68 LGSE son taxativos además por una razón de contexto legal: ellos constituyen el correlativo de los derechos que las servidumbres eléctricas otorgan a los concesionarios; así:

a) Se indemniza el terreno ocupado (art. $68 \mathrm{n}^{\circ} 1$ LGSE) porque el concesionario tiene derecho a instalar postes y torres y a trazar caminos de acceso (según arts. $2 \mathrm{n}^{\circ} 4 \mathrm{a}$ ), 50, 55 y 56 LGSE. Entonces, el art. $68 \mathrm{n}^{\circ} 1$ LGSE es correlativo de estos dos últimos artículos;

b) Se indemniza los perjuicios del ejercicio de las servidumbres, y en especial los que causan las líneas aéreas (art. $68 \mathrm{n}^{\circ} 2$ LGSE), porque el concesionario puede tender líneas a través del predio (art. 50 LGSE), lo que limita al dueño del predio (art. 56 LGSE). Se da igualmente esta correlación.

c) En fin, se indemniza el tránsito (art. $68 \mathrm{n}^{\circ} 3$ LGSE), porque el concesionario puede llevar a cabo tal tránsito (arts. 55 y 57 LGSE), en que se da igualmente la correlación.

Entonces, no hay indemnizacion posible en los casos en que el propietario del predio sirviente puede usar plenamente su terreno y, además, no exista ningún 
derecho correlativo que pueda ejercer en tales terrenos el concesionario eléctrico, goce por el cual deba pagar una indemnización al que los deba soportar como gravamen. Esta lógica que debe presidir en los supuestos indemnizatorios de toda servidumbre: si no hay servidumbre, no hay perjuicio, ni consiguientemente, indemnización.

\section{CONCEPTO DE «TERRENOS OCUPADOS» PARA LOS EFECTOS DEL "AUMENTO» EXCEPCIONAL DE MONTO DE INDEMNIZACIÓN EN LAS SERVIDUMBRES ELÉCTRICAS PREDIALES}

La cuestión de la correcta interpretación del art. 69 LGSE, es usualmente discutida por las partes interesadas en los juicios de reclamación del avalúo de las indemnizaciones qué, a raíz de servidumbres prediales eléctricas, deban pagarse al propietario del predio sirviente.

Como es sabido, si no se produce acuerdo entre el concesionario eléctrico y el dueño del predio que debe soportar las servidumbres eléctricas, el avalúo de las indemnizaciones es practicado por una Comisión de Hombres Buenos (art. 62 LGSE), para lo cual la ley establece una regulación específica en los arts. 63 a 69 LGSE, y un procedimiento legal (arts. 70 y 71 LGSE).

En especial, la ley enumera (art. 68 LGSE) los distintos tipos de limitaciones que sufre el dueño de un predio sirviente, de las que se originan perjuicios por los que se le debe indemnizar, como son: los perjuicios por las ocupaciones de terrenos por obras, instalaciones de postes, torres y caminos; los perjuicios ocasionados durante la construcción de las obras, y los derivdos del ejercicio de las servidumbres, en especial, y por las líneas aéreas; y, en fin, los perjuicios ocasionados por el tránsito que se debe efectuar para la custodia, conservación y reparación de las líneas (todo ello analizado supra).

Agrega la ley (en el art. 69 LGSE), a continuación de la anterior enumeración, que los «terrenos ocupados», se pagarán, a tasación de peritos, "con veinte por ciento de aumentos.

Entonces, por ejemplo, en el caso de la servidumbre de postes y líneas eléctricas (que favorecen a un concesionario de transporte de energía eléctrica), surge el siguiente problema: ¿qué se entiende por «terrenos ocupados»? ¿Aquéllos en que existe instalado y construido un poste o una torre, esto es, en que se ocupa físicamente terrenos? ¿O también se puede entender que es iterreno ocupado" aquél que sufre limitaciones derivadas de una línea eléctrica que pasa «a través» de tal terreno? ¿«Ocupa terrenos«, para los efectos de este «aumento», el tendido de una línea aérea que pasa "a través» de un predio, de tal manera que el perjuicio que se pague al propietario sea objeto de un aumento del veinte por ciento? 
Para obtener una respuesta a esta cuestión, se analiza el concepto jurídico de "terreno ocupado», y de lo cual surge, si al igual que un poste o una torre, la línea aérea «ocupa» terrenos.

Cabe reiterar que, el art. 69 LGSE establece: «Los terrenos ocupados se pagarán, a tasación de peritos, con veinte por ciento de aumento». Al analizar las palabras (verba) de la ley (A), y el sentido (sensus legis) de la ley, que emana de su contexto (B), podremos concluir que sólo es posible entender que es uterreno ocupado", en materia de instalaciones eléctricas, aquella porción de "tierra» cuyo «espacio ha sido llenado» por obras o instalaciones eléctricas, y que quedan inutilizados para todo otro uso: por eso la ley no sólo contempla el pago de «todo» su valor (art. $68 \mathrm{n}^{\circ} 1$ LGSE), sino además un «aumento» (art. 69 LGSE); aumento éste que se presenta como excepcional y restrictivo sólo para este caso de ocupación física y total de un terreno o inutilización para todo otro uso. Además, este ha sido el criterio de la jurisprudencia judicial, y de la práctica administrativa (C).

\section{A/Palabras de la ley (verba)}

El primer análisis dice relación con el significado de las palabras (significatio verborum). Al respecto, según el art. $20 \mathrm{CC}$ que «[] as palabras de la ley se entenderán en su sentido natural y obvio, según el uso general de las mismas palabras». La jurisprudencia ha dicho que sentido natural y obvio es el que a las palabras da el Diccionario de la Real Academia Española ${ }^{7}$; y tal diccionario en su edición de 2001 señala que «ocupar» significa: «[t]omar posesión o apoderarse de un territorio, de un lugar, de un edificio, etc., invadiéndolo o instalándose en él" /(...)/ 3. Llenar un espacio o lugan>.

De modo que de acuerdo al sentido natural y obvio de las palabras sólo es posible entender por terrenos ocupados aquellos que lo están física o materialmente (y que «llenan un espacio o lugan»). La verdad es que, la idea misma de «terrenos ocupadoss implica necesariamente la ocupación material o física de un terreno; y así fluye entendiendo las palabras en su sentido natural y obvio, que es lo que corresponde al interpretar este art. 69 LGSE.

El texto del art. 69 LGSE es claro: el aumento del veinte por ciento es aplicable únicamente respecto de los «terrenos ocupados». Ahora bien, la cuestión es precisar a qué se refiere la ley al hablar de «terrenos ocupados». No debe olvidarse que tal art. 69 LGSE contiene una hipótesis legal relativa a la ocupación territorial; en que se unen dos palabras: occupare (instalarse, llenar un espacio) y terrenus (sitio o espacio de tierra).

Fiste criterio interpretativo es generalmente aceptado, salvo palabra técnica de alguna ciencia o arte. Vid.: Alessandri, Arturo y otros, Derecho Cinil. Parle Preliminar y Parle General (Santiago, Ediar Conosur Ltda, 1990), pág. 174. 
A partir de lo anterior, podemos entender que de acuerdo a la etimología latina de ambas expresiones, un «terreno» está «ocupado», cuando alguna obra o instalación «llena un espacio de tierra». Este es, además, el sentido natural y obvio que en el idioma español resulta de las palabras que utiliza el legislador.

\section{$\mathrm{B} / \mathrm{El}$ sentido y contexto de la ley (sensus legis)}

Conexo y complementario al texto o palabra (verba) de la ley, es su contexto: sirve para determinar si es posible entender las palabras de la ley de un modo distinto o igual al claro sentido que fluye de ese contexto. Al respecto el art. 22 Código Civil establece en su inc. $1^{\circ}$ que: " $[e] l$ contexto de la ley servirá para ilustrar el sentido de cada una de sus partes».

Al respecto, y considerando el texto y contexto del art. 69 LGSE, podemos efectuar las siguientes consideraciones:

a) La expresión «terrenos ocupados» utilizada por el legislador en tal art. 69 LGSE, ya había sido utilizada en el art. $68 \mathrm{n}^{\circ} 1$, intimamente conectado con éste, y en esta última norma su sentido es claro: se trata del terreno «ocupado (...) por los postes y las torres de las lineas" (que es el caso que ahora nos interesa) o, (por las zanjas de las lineas subterráneas» o, "por los edificios» o «por los caminos de acceso, según los planos de servidumbres». Resulta evidente que, de acuerdo a la ley, es parte esencial del concepto «terrenos ocupados» la materialidad de la ocupación.

b) La ley al determinar las indemnizaciones a las que tiene derecho el dueño del predio sirviente, establece, según vimos, tres aspectos distintos, por los que se deben calcular valores a pagar: los señalados en los números 1,2 y 3 del art. 68 LGSE. Sólo uno de ellos $\left(\mathrm{el} \mathrm{n}^{\circ} 1\right)$ se refiere específicamente al pago de indemnización por «terrenos ocupados»; y resulta evidente que los otros dos casos (n ${ }^{\circ}$. 2 y 3) tratan de indemnizaciones por otros conceptos o limitaciones que no se derivan de la ocupación de terrenos. De la sola lectura del art. 68 LGSE resulta obvio que el legislador entiende que no todas las indemnizaciones debidas al dueño del predio sirviente lo son por los «terrenos ocupados» ( $\left.\mathrm{n}^{\circ} 1\right)$, y así se encarga de precisarlo señalando que también se debe indemnizar las limitaciones (perjuicios) que producen las líneas aéreas $\left(\mathrm{n}^{\circ} 2\right)$, y el tránsito hacia ellas $\left(\mathrm{n}^{\circ} 3\right)$, aunque eso no implique «ocupar» un terreno.

c) Sólo en dos ocasiones la ley se refiere a «terreno (s) ocupado (s) »: en el art. 68 $n^{\circ} 1$ LGSE y en el 69 LGSE; por lo que de ahi surge una correspondencia y armonia evidente, a partir de lo cual sólo podemos entender que el sentido de la expresión «terreno (s) ocupado (s)» utilizada en el art. 68 es idéntica al sentido de igual expresión utilizada en el art. 69 LGSE.

d) El art. $68 \mathrm{n}^{\circ} 3$ LGSE utiliza la expresión "predio ocupado» al establecer un límite al monto de la indemnización por el tránsito que el concesionario tiene derecho a hacer para los efectos de la custodia, conservación y reparación de las líneas. Como el legislador no distingue, debe entenderse que esta norma se refiere 
tanto a las líneas aéreas como a las líneas subterráneas. Para comprender esta limitación o gravamen indemnizable debe recordarse que el art. $50 \mathrm{n}^{\circ} 1 \mathrm{LGSE}$, al referirse a las líneas, señala que el derecho de servidumbre permite itender líneas aéreas (...) a través de propiedades ajenas», de lo que resulta que tales líneas no ocupan terreno, sino que se "tienden», «a través» de un predio, lo que está considerado como perjuicio en el art. $68 \mathrm{n}^{\circ} 2$ parte final LGSE. De este modo, de una interpretación armónica de los arts. $50 \mathrm{n}^{\circ} 1$ y $68 \mathrm{n}^{\circ} \mathrm{s} 1,2$ y 3 LGSE resulta que el legislador comprende que las líneas eléctricas no "rocupan» terreno, sino que "cruzan» el predio, y tal cruzamiento está indemnizado separadamente, por la limitación que ellas originan (art. 56 LGSE), y no por que ocupen un terreno, pues eso no sucede.

La indemnización por este concepto se refiere al tránsito que tiene derecho a hacer el concesionario eléctrico para la conservación, custodia y reparación de las líneas. Como tal, la limitación que sufre el predio por el derecho al tránsito del concesionario no se refiere sino indirectamente a una franja de terreno determinado: la limitación y gravamen consiste en soportar este tránsito para los fines que establece la ley (arts. 55 inc. $1^{\circ}$ y 57 LGSE); y si se habla de «franja» de tránsito es porque la ley ha establecido como criterio, de un modo ficto, para la determinación del monto máximo de esta indemnización, la siguiente regla: resta indemnización no podrá ser superior al valor de una faja de terreno de dos metros de ancho, en la parte del predio ocupado [urruqadon, mas bien] por las lineas» (art. $68 \mathrm{n}^{\circ} 2$ in fine LGSE). Regla que no cambia la naturaleza de esta limitación: soportar el derecho a tránsito, el que se efectúa por un camino de acceso.

La ley entiende, entonces, que por una parte, para los efectos del cálculo de las servidumbres, los «caminos de acceso», constituyen una ocupación «total» (y se deben indemnizar por toda la superficie que cubre el trazado de esos caminos: art. $68 n^{\circ} 1$ LGSE); y que, por otra parte, el tránsito para los efectos de la custodia, conservación y la reparación de las líneas, constituye un gravamen cuyo avalúo se debe hacer, de manera ficta, considerando el valor de una "faja de terreno" de dos metros de ancho. Es comprensible, entonces, para el intérprete que la ley no entiende que este terreno está «físicamente» ocupado, sino que es sólo un modo de efectuar un cálculo de la indemnización. En la práctica, esta "franja de tránsito» se tasa según el máximo legal: según el valor de un terreno de dos metros de ancho por toda la longitud de la línea aérea, tasado en un cien por ciento de su valor (valor éste al que no le corresponde el aumento del veinte por ciento a que se refiere el art. 69 LGSE, pues no es un "terreno ocupado" propiamente).

La jurisprudencia judicial ha reafirmado a éste como el criterio adecuado para comprender el concepto de «terrenos ocupados» en el texto y contexto del art. 69 
LGSE; así; la sentencia de la Corte Suprema, de 22 de septiembre de $1997^{\circ}$, señala de modo enfático que:

«De los artículos $68 \mathrm{n}^{\circ} 1$ y 69 del DFL $\mathrm{n}^{\circ} 1$ fluye que el recargo contemplado en el citado artículo 69 sólo es aplicable al valor que se determine para los terrenos que efectivamente ocupe la línea que causa la servidumbre, sin extenderse a los restantes valores que comprenda la indemnización, por no existir a su respecto la misma razón que los justifica en el caso del $n^{\circ} 1$ del artículo 68, ya que en esos casos el propietario del predio sirviente no se ve privado de los bienes respectivos, sino limitado en su uso y aprovechamiento: en consecuencia, al haber determinado la sentencia impugnada que el recargo se aplicaría a la totalidad de los valores determinados ha incurrido en un error de derecho que resulta bastante para anularla, el que ha influido en lo dispositivo del fallo, pues de no mediar aquél, distinto y menor habria sido el monto a que resultó condenado el demandadom.

e) Dos argumentos de contexto adicionales permiten concluir que la ley entiende por terrenos ocupados sólo aquéllos en que físicamente se instalan postes, torres y caminos de acceso (en el caso de la servidumbre de un concesionario de transporte de energía eléctrica):

$1^{\circ} \mathrm{La}$ ley considera que está mayormente gravado el terreno efectivamente ocupado, el que queda «inutilizado» para su natural aprovechamiento, y por eso sólo respecto de estos terrenos se establece una indemnización total y un aumento excepcional del veinte por ciento del avalúo de su indemnización. El resto de los terrenos sólo sufren limitaciones que no consisten en su ocupación física o en su inutilización para su natural aprovechamiento, las que deben ser indemnizadas de acuerdo a otros criterios. Recuérdese que sólo respecto de los terrenos ocupados

\footnotetext{
Caso «Zeman con Chilectra», fallado por Corte de Apelaciones de San Miguel, 26 de septiembre de 1996, y Corte Suprema, en fecha indicada (Sentencias de casación y de reemplazo). Inédito. Existen dos oficios de la Superintendencia de Electricidad y Combustibles:

a) Oficio $\mathrm{n}^{\circ} 1.922$, de 5 de junio de 1997, que responde a una consulta realizada por Chilectra S.A. sobre la correcta interpretación de los arts. 65, 68 y 69 LGSE, según el cual: «Fluye con claridad que la indemnización que recibe el aumento indicado [del veinte por ciento] es la contemplada en el artículo 69, esto es, aquella vinculada al valor de los terrenos ocupadosw; y que: «Si se considera que el legislador se ha preocupado de señalar, en el artículo 68 del antedicho DFL $\mathrm{n}^{\circ} 1$, cuáles son las indemnizaciones que corresponde pagar al dueño del predio sirviente definiendo tres rubros específicos que deben ser reparados pecuniariamente, incluyendo entre ellos uno especialmente dedicado al valor de todo terreno ocupado, siguiendo la regla de hermenéutica estatuida en el artículo 22 del Código Civil que indica que el contexto de la ley servirá para ilustrar el sentido de cada una de sus partes, de manera que haya entre todas ellas la debida correspondencia y armonia, resulta forzoso concluir que el aumento del veinte por ciento mencionado es aplicable exclusivamente respecto de la indemnización relativa al valor de los terrenos ocupados $\mathrm{y}$, por ende, no es procedente en cuanto al monto del resto de las prestaciones que también deben compensarsem.
}

b) Oficio n 1.607, de 23 de marzo de 1999, en que responde a una consulta realizada por la Empresa Eléctrica ColbúnMachicura S.A., respectó de si el criterio sostenido en el Oficio $n^{\circ}$ 1.922, de 5 de junio de 1997 , reviste el carácter de una instrucción general y por ende, corresponde ser aplicado al pago de indemnizaciones por las servidumbres constituidas para el establecimiento de la línea de transporte de energía eléctrica de 220 kv. denominada Polpaico-Maitenes. La respuesta de la Superintendencia señala lo siguiente: $1^{\circ}$ El criterio sostenido en el Oficio $\mathrm{n}^{\circ}$ 1.922: ves de aplicación general para todos las casos que sean de ignal naturale aju, a partir de la fecha de ese oficio; $\mathrm{y}, 2^{\circ}$ Para el proyecto de la línea eléctrica de que se trata (línea de transporte de energía eléctrica denominada Polpaico- Maitenes), wel aumenta del vinte por ciento sólo es up licable al valor de todo terrino ocupado por las postes, o las torres, y los caminos de acceso, seguin lor planos de senvidumbreso. 
(por los postes, torres y caminos de acceso en este caso), no se podrán efectuar plantaciones, construcciones ni otras obras; y, por el contrario, en aquellos otros terrenos «cruzados» con las líneas aéreas o subterráneas (y por lo cual se paga igualmente indemnización: art. $68 \mathrm{n}^{\circ} 2$ LGSE), el dueño del predio podrá hacer tales plantaciones, construcciones y obras, siempre que no perturbe el ejercicio de la servidumbre (art, 56 LGSE).

$2^{\circ}$ Además, pretender que el aumento del art. 69 LGSE opera sobre todos los rubros que se indican en el art. 68 LGSE, sería alterar los términos en que la ley concibe la fijación de la indemnización por la Comisión de Hombres Buenos (o por el juez, en caso de reclamación). En efecto, el art. 65 LGSE, señala que «[e]l valor fijado por la comisión de Hombres Buenos, más el veinte por ciento de que trata el articulo 69, será entregado al propietario (...) m. De lo que fluye que según este art. 65 LGSE, no es que el valor total fijado por la Comisión [que incluye los tres casos del art. 68 LGSE] se deba aumentar en un veinte por ciento, sino que se aumenta con el veinte por ciento «de que trata el artículo 69", esto es, en el veinte por ciento de aumento del valor de los «terrenos ocupados». Dicho de otro modo, si la hipótesis que estableció el legislador hubiese consistido en que el valor total fijado por la comisión de Hombres Buenos debía aumentarse en un veinte por ciento, así lo habría dispuesto expresamente.

f) De todo lo cual resulta que la ley opera del siguiente modo: el dueño del predio sirviente sólo tiene derecho a que se le indemnice en las siguientes tres hipótesis de limitaciones o gravámenes a su propiedad:

$1^{\circ}$ por los «terrenos ocupados» (art, $68 \mathrm{n}^{\circ} 1 \mathrm{LGSE}$ );

$2^{\circ}$ por los perjuicios ocasionados durante la construcción o ejercicio de las servidumbres, dentro de lo cual se contemplan los perjuicios que causan las líneas aéreas que se tienden «a través» del predio (arts. $68 \mathrm{n}^{\circ} 1$ y $50 \mathrm{n}^{\circ} 1$ LGSE); y

$3^{\circ}$ por el tránsito, en su caso (art. $68 \mathrm{n}^{\circ} 3$ LGSE).

En el único caso de estas tres hipótesis en que se opera sobre la base de una "rocupación de terreno», física y total, en que quedan inutilizados para su natural aprovechamiento, es en el primero de los casos enumerados. Por lo tanto, la conclusión fluye nítida: sólo respecto de los terrenos fisica y totalmente ocupados, e inutilizados para otro aprovechamiento, a que se refiere el art. $68 \mathrm{n}^{\circ}$ LGSE, podrá aplicarse la hipótesis complementaria del art. 69 LGSE, y de manera restrictiva, de tal manera que sólo respecto de ellos es posible que la comisión de Hombres Buenos (o el juez, en su caso) aplique un veinte por ciento de aumento excepcional al avalúo de la indemnización que deba pagarse al dueño del predio sirviente. 


\section{LA FRANJA «AFECTACIÓN INDIRECTA» Y EL «IMPACTO AMBIENTAL» DE POSTES Y LÍNEAS AÉREAS, COMO PERJUICIOS INDEMNIZABLES}

Según se desarrolló en el caso de las servidumbres eléctricas prediales que son constituidas en el decreto de concesión, si no se produce acuerdo entre el concesionario eléctrico y el dueño del predio superficial sobre la indemnización a pagar por tales servidumbres, tal fijación la deberá efectuar una comisión de Hombres Buenos. Al respecto, la ley establece una serie de normas, tanto procedimentales como sustantivas, por las que debe regirse esta comisión de Hombres Buenos en su trabajo de avaluación de las indemnizaciones; normas estas que, en caso de reclamación judicial, deberá hacerlas respetar el juez.

En general, el informe del avalúo efectuado por la comisión de Hombres Buenos debe establecer los criterios de tasación de los perjuicios para el propietario del predio sirviente; y estos perjuicios se derivan de las limitaciones que sufre en el normal uso de su terreno.

Al respecto, para guiar a la Comisión de Hombres Buenos (y al juez, en su caso) en el establecimiento de tales criterios de tasación en cada caso concreto, señala la ley sólo tres tipos de limitaciones al uso del terreno que deben ser indemnizadas (art. 68 LGSE): (i) las ocupaciones territoriales; (ii) el uso del terreno para el ejercicio de las servidumbres, y las propias líneas eléctricas que cruzan un terreno; limitación ésta que, en la práctica, ha originado una «franja de servidumbre», de 40 metros de ancho, en la cual, entre otras limitaciones, no se podrán realizar plantaciones superiores a los 4 metros de altura, ni tampoco construir; (iii) en fin, el tránsito (vid. supra, I).

Estos son entonces los tres tipos de limitación al terreno que la ley eléctrica considera como indemnizables, y por los cuales el dueño del predio sirviente tiene derecho a que se le pague indemnización. Es en este contexto que se plantean las siguientes interrogantes:

a) ¿Es legítimo que en el avalúo practicado por la Comisión de Hombres Buenos se incluya una ifranja de influencia indirectas? Al respecto, cabe preguntarse si la ley permite a la comisión de Hombres Buenos fijar una franja, por ejemplo, de 100 metros a cada lado y a todo lo largo de una línea eléctrica en caso que se estime que en ese espacio de terreno la línea aérea tendría «influencia», aunque en menor grado, en alguno de los componentes que conforman el valor del suelo.

La situación es trascendente dado que a raíz de lo cual ha habido casos en que la Comisión de Hombres Buenos acuerda una indemnización equivalente al 30 por ciento del valor de los terrenos comprometidos a favor del dueño ¿Es legítimo este criterio de indemnización?

Al respecto, deberá considerarse, como se acaba de recordar, que señala el art. 68 LGSE, las limitaciones por las que deben pagarse indemnizaciones al propietario del predio sirviente, y cuyo avalúo para cada caso específico queda 
entregado a la Comisión de Hombres Buenos, si no existe acuerdo entre el concesionario y el dueño del terreno. De este modo, cabe preguntarse si ante tal enumeración expresa y taxativa (vid. supra, I), ¿tal comisión es libre para determinar qué limitaciones indemnizar? ¿O, por el contrario, se encuentra limitada a los términos de la ley? ¿Es posible considerar una «franja de influencia indirecta» (de las líneas aéreas) dentro de las hipótesis contenidas en el art, 68 LGSE?

b) Por otra parte, en el ejercicio de la acción de reclamación del art. 67 LGSE, ¿podría el propietario del predio sirviente, invocar como indemnizables a su favor los eventuales impactos ambientales sobre la flora, vegetación, paisaje y patrimonio cultural y arqueológico? ¿Qué efectos tiene en la fijación de indemnizaciones la aprobación de un Estudio de Impacto Ambiental, obligatorio en el caso de las líneas de transmisión eléctrica de alto voltaje y sus estaciones (art. 10 letra b) ley n 19.300 de 1994, sobre Bases Generales del Medio Ambiente)? ¿Es esta la sede jurisdiccional adecuada para invocar perjuicios por impactos ambientales? ¿Puede un particular invocar a su favor indemnizaciones por eventuales impactos ambientales?

Cabe preguntarse si es posible que la Comisión de Hombres Buenos o el juez al resolver el reclamo de la tasación de tal comisión, tienen la posibilidad jurídica de establecer como limitación del predio sirviente, y por lo tanto con derecho a indemnización, lo que se ha denominado «influencia indirecta» y los daños o impactos ambientales.

Para ofrecer una respuesta, se debe analizar la legalidad, en relación a las atribuciones que la ley otorga a la Comisión de Hombres Buenos y al juez, para establecer indemnizaciones (criterios generales analizados supra); y, luego, en relación a las indemnizaciones a las que según la ley tiene derecho el dueño del predio, verificar si tienen cabida tales influencias indirectas e impactos ambientales (lo que se analiza en seguida).

A/Posibilidad de considerar como limitación indemnizable la sinfluencia indirectas de las líneas aéreas.

1. La llamada «influencia indirecta» es un concepto extra legal. $\mathrm{Al}$ analizar si es procedente una indemnización por la denominada «influencia indirecta» que se produciría en una franja lateral a las líneas y en toda su longitud, de partida debemos señalar que se trata de una limitación o gravamen no contemplado expresamente en la ley especial eléctrica (pues no se ejerce en tal franja de «influencia indirecta» ningún derecho por el concesionario eléctrico, ni se efectúa ninguna ocupación territorial). En especial, no está contemplado en el art. 68 LGSE, que establece las indemnizaciones a las que tiene derecho el dueño del predio sirviente, norma que como hemos demostrado, tiene un carácter taxativo.

Así, al analizar la norma contenida en tal art. 68 LGSE se puede constatar que la «afectación indirecta» no está comprendida en la enumeración legal. La 
norma no se refiere expresamente a una indemnización por "afectación indirecta», por lo tanto, se debe analizar si tal «afectación» podría considerarse comprendida en alguno de los tres casos establecidos en la ley, ya estudiados (vid. supra, I):

a) Se debe descartar que la llamada ufranja de afectación indirecta» esté contenida en las hipótesis de los números 1 y 3 del art. 68 LGSE, pues aparece de manifiesto, de su sola denominación, que la sinfluencia» no puede ser considerada «terreno ocupado»; además, es imposible concebir una ocupación «indirecta» de terreno; o entender que «ocupación» e «influencia» son una misma cosa.

b) No se trata tampoco de «terrenos inutilizados para su natural aprovechamiento» en los términos del inciso final del art. 68 LGSE, pues (según los casos de informe de tasación de Hombres Buenos que han realizado eseta rara fijación), la llamada «franja de afectación indirecta» sería una franja de terreno respecto de la cual la línea eléctrica tiene sinfluencia, aunque en menor grado, en alguno de los componentes que conforman el valor del suelos, y no podría decirse que esta influencia, así concebida, según las condiciones señaladas por tal informe, implica una «inutilización» del terreno para su natural aprovechamiento.

c) Queda por indagar si esta (influencia indirecta» está contenida en las hipótesis del art. $68 \mathrm{n}^{\circ} 2$ LGSE. De partida, resulta evidente que las responsabilidades establecidas en la primera parte de la norma, respecto de perjuicios ocasionados «durante» la construcción de las obras o «como consecuencia de ellas» o «del ejercicion de las servidumbres, no pueden comprender una indemnización como la analizada. Cuando la ley se refiere a los perjuicios ocasionados «durante» «el ejerciciò de las servidumbres, está haciendo referencia a los derechos o facultades que éstas confieren a su titular, derechos y facultades que dicen relación con terrenos determinados, los cuales quedan claramente establecidos en los respectivos planos de servidumbres. $Y$ se puede afirmar que, respecto de los terrenos comprendidos en la llamada "franja de afectación indirecta", el titular de las servidumbres eléctricas no tiene derecho ni facultad alguna, por lo tanto, es impensable que cause perjuicios en tales terrenos.

Aún cuando se tuviera un concepto distinto o más amplio de lo que debe entenderse por «perjuicios ocasionados durante el ejercicio de las servidumbress, se debe entender que ellos no comprenden los causados por el tendido de las líneas eléctricas, pues el art. 68 LGSE analizado se refiere de manera separada a ambos (en sus incisos $1^{\circ}$ y $2^{\circ}$ ).

2. Los terrenos que no sufren limitación o kinutilización» no son indemnizables. Entonces, debemos determinar si existe la posibilidad de fijar una indemnización por la «afectación indirecta» que unas líneas aéreas puedan ocasionar en una "franja» de terreno del predio sirviente. La ley dice que kel dueño del predio sirviente tendrá derecho a que se le pague (...) el valor de los perjuicios ocasionados por las líneas aéreas») (art. $68 \mathrm{n}^{\circ} 2$ in fine LGSE): ¿pueden considerarse entre estos perjuicios las llamadas «influencias indirectas»? 
Como se dijo antes (supra I, 5 y 6), procede indemnizar respecto de terrenos efectivamente limitados e inutilizados por las líneas eléctricas, por lo que ante la hipótesis de unos perjuicios tan vagos (como, por ejemplo kuna influencia, aunque en menor grado, en algunos de los componentes que conforman el valor del suelon), en que no queda claro en qué consiste específicamente el perjuicio, se puede suponer que al hablarse de algunos no afecta a todos los componentes del valor del suelo, pero a cuáles y de qué modo, es algo que no se menciona, no son perjuicios indemnizables ni aún cuando se tratara de perjuicios «ilícitos», pues no cumplen los requisitos de ser perjuicios ciertos (daño real y efectivo), ni directos (consecuencia cierta y necesaria, forzosa de la acción u omisión que los causa), menos aún pueden considerarse perjuicios indemnizables si son perjuicios «lícitos» (según se verá infra).

La jurisprudencia ha señalado: "Que de acuerdo a los principios establecidos en el artículo 68 del DFL $\mathrm{n}^{\circ} 1$ no corresponde considerar indemnización por lo que el informe pericial de fs. 162 determina como faja de contaminación y remanente de lotes, aún cuando el trazado de la línea ejerza una influencia negativa sobre el proyecto de loteo que el reclamante tenía proyectado ejecutar, ni tampoco corresponde hacer aplicación de la norma contenida en el inciso final del artículo 68 del DFL $68 n^{\circ} 1$, porque los terrenos sobre los cuales se constituye servidumbre no quedan inutilizados para su natural aprovechamiento»?

En otras palabras, utilizando las expresiones ifaja de contaminación» e «influencia negativa), similares a las que se refiere este capítulo (《influencia indirecta» e «impacto ambientaly), se ha rechazado por la Corte Suprema la inclusión de nuevas limitaciones indemnizables que no se encuentren en el art. 68 LGSE.

Por lo tanto, se desprende de este pronunciamiento judicial que aunque en algunos terrenos exista una imfluencian, por negativa que sea, no procede indemnización alguna, a menos que se pruebe que han quedado kinutilizados para su natural aprovechamienton, situación que no se da ni siquiera en el caso de las servidumbres.

Además, al no haber servidumbre sobre ellos, no hay posibilidad de fijar indemnización (sería una petición de principios, entonces, fijar indemnización respecto de terrenos a los que no se rextiende» la servidumbre, como lo señala el art. 68 inc. final LGSE.

$\mathrm{B} /$ Posibilidad jurídica de indemnizar el impacto ambiental de las líneas aéreas

Se plantea la posibilidad jurídica de exigir al concesionario eléctrico una indemnización a favor del propietario del predio sirviente, por los eventuales daños o impactos ambientales.

\footnotetext{
9 En el caso "Zeman con Chilectraw, fallado por sentencia de la Corte Suprema, de 22 de septiembre de 1997, se contiene la siguiente afirmación (en el considerando 15 de la sentencia de la Corte de Apelaciones de San Miguel, de 26 de septiembre de 1996, en una parte que da por reproducida la Corte Suprema).
} 
El fundamento de la obligación de indemnizar el daño en la sflora, vegetación, patrimonio cultural y arqueológico», sería, por quienes así lo invocan, el art. $68 \mathrm{n}^{\circ} 2$ LGSE, que establece que el dueño del predio sirviente tiene derecho a que se indemnice «el valor de los perjuicios ocasionados durante la construcción de las obras o como consecuencia de ellas o del ejercicio de las servidumbres. Igualmente el valor de los perjuicios que causan las líneas aéreas».

En realidad, la ley eléctrica no contempla indemnización alguna por un supuesto impacto ambiental en las superficies afectadas por las líneas aéreas en su «flora, vegetación, patrimonio cultural y arqueológico», ni podría colegirse del art. 68 LGSE, dados sus términos taxativos.

Al respecto cabe recordar que, de acuerdo al art. 10 Ley $n^{\circ} 19.300$, de 1994, sobre Bases Generales del Medio Ambiente, todo proyecto de rlineas de transmisión eléctrica de alto voltajes, debe ser sometido al Sistema de Evaluación de Impacto Ambiental. Y, una vez sometido a tal sistema, si se ha dictado una resolución favorable que autoriza a ejecutar el proyecto, y se ha certificado por los órganos competentes que «se cumple con todos los requisitos ambientales aplicables» (art. 24 Ley N ${ }^{\circ}$ 19.300), se excluye toda posibilidad de que la ejecución del proyecto en los términos en que fue aprobado cause un «daño ambiental» o «impactos ambientales» o «influencias ambientales negativas», o como quiera llamárselas, por las cuales deba indemnizarse.

Además, dada la amplitud del ámbito territorial que podría considerar que sufre «impacto ambiental» (kilómetros a cada costado de las líneas eléctricas, en los casos que en la práctica se ha invocado), podría llegar a decirse que los propietarios de los terrenos vecinos al eventualmente afectado también podrían llegar a solicitar, en su caso, indemnización; lo cual es abiertamente excesivo.

Por otra parte, es importante tener presente que la Ley $\mathrm{N}^{\circ} 19.300$, establece, siguiendo la regla general en nuestro ordenamiento jurídico, como elemento fundamental del «daño ambiental» la existencia de culpa o dolo, esto es, responsabilidad subjetiva. Y si bien, la misma ley establece que prevalecerán las normas sobre responsabilidad por daño al medio ambiente contenidas en leyes especiales, no puede considerarse, que la disposición contenida en el art. $68 \mathrm{n}^{\circ} 2$, parte final, LGSE (que establece que el dueño del predio sirviente tiene derecho a que se le pague el valor de los perjuicios que causen las líneas aéreas), contempla una responsabilidad objetiva respecto de los efectos ambientales causados. Y ello es improcedente no sólo porque al tratarse de una actividad sujeta al Sistema de Evaluación de Impacto Ambiental y al dictarse una resolución favorable no cabe hablar de "daño ambiental", sino también porque para modificar el sistema general sobre responsabilidad ambiental (que opera sobre la base de responsabilidad subjetiva), debe necesariamente hacerse de modo expreso, o a lo menos, debe fluir claro que la norma así lo hace, de los términos en que está redactada. 
Además, si se revisa la normativa ambiental del caso, se verá una similitud en la terminología invocada por quienes sustentan la posibilidad de indemnización por "afectación indirecta", como por "daños ambientales»: en ambos casos se trataría de "impactos», "influencias», "ralteraciones» en áreas circundantes a las instalaciones eléctricas, y en superficies no contempladas estricto sensu en el art. 68 LGSE. Es indudable que la única referencia normativa es el art. 2 letras j), k) y l) Ley $\mathrm{N}^{\circ}$ 19.300, y todas estas "influencias», «impactos» o «alteraciones» son admisibles en el ordenamiento chileno, salvo que sean «significativos», pues en este último caso, no podrían ejecutarse los proyectos respectivos.

Por lo tanto, si un proyecto de «línea de transmisión eléctrica» (art. 8 letra b) Ley $\mathrm{N}^{\circ} 19.300$ ) ha recibido resolución favorable del proceso de evaluación ambiental (art. 24 ley $\mathrm{N}^{\mathrm{o}}$ 19.300), y al respecto, en su caso, se han establecido las medidas de mitigación o restauración ambiental, no puede, al mismo tiempo, exigírsele que indemnice al dueño de los predios respectivos por tales conceptos, no sólo porque la ley entiende que no hay impacto ambiental, sino porque las personas no se pueden enriquecer por supuestos daño a la naturaleza, los que, según nuestro sistema, o están prohibidos o se deben mitigar o restaurar.

En fin, para ambos casos (A y B), las limitaciones producidas por las servidumbres eléctricas son los únicos perjuicios que ocasionan las líneas eléctricas aéreas que, de acuerdo al tenor y espíritu de la ley eléctrica, es posible considerar como indemnizables (vid supra, I, 6), por lo que posibles «influencias» o «impactos» sean calificados de «indirectos» o "ambientales», que pueda percibirse que produce una línea eléctrica, y que no consisten en una efectiva limitación ni gravamen directo al dueño del predio sirviente ni originan derechos de que pueda gozar el titular de una servidumbre eléctrica, no están contenidas entre los posibles perjuicios a pagar en el caso de las servidumbres eléctricas. 